\title{
Correction to: Three-Year Results from the Venovo Venous Stent Study for the Treatment of Iliac and Femoral Vein Obstruction
}

\author{
Michael D. Dake ${ }^{1} \cdot$ Gerard O'Sullivan $^{2} \cdot$ Nicolas W. Shammas $^{3} \cdot$ Michael Lichtenberg $^{4}$ • \\ Bibombe P. Mwipatayi ${ }^{5}$. Richard A. Settlage ${ }^{6}$ for the VERNACULAR Trial \\ Investigators
}

Published online: 19 October 2021

(C) Springer Science+Business Media, LLC, part of Springer Nature and the Cardiovascular and Interventional Radiological Society of Europe (CIRSE) 2021

\section{Correction to: Cardiovasc Intervent Radiol https://doi.org/10.1007/s00270-021-02975-2}

The original article has been corrected. This article was updated to correct the formatting of Table 3 which occurred after authors reviewed proofs.
Publisher's Note Springer Nature remains neutral with regard to jurisdictional claims in published maps and institutional affiliations.
The original article can be found online at https://doi.org/10.1007/ s00270-021-02975-2.

Michael D. Dake mddake@arizona.edu

Gerard O'Sullivan gerard.osullivan2@hse.ie

Nicolas W. Shammas shammas@mchsi.com

Michael Lichtenberg klichte@gmx.net

Bibombe P. Mwipatayi patrice@bibombe.com

Richard A. Settlage rasettlage@msn.com
University of Arizona Health Sciences, Health Sciences Innovation Building, 9Th Floor SVP Suite, 1670 E. Drachman Street, P.O. Box 210216, Tucson, AZ 85721-0216, USA

2 University Hospital Galway, Galway, Ireland

3 Midwest Cardiovascular Research Foundation, Davenport, IA, USA

4 Arnsberg Vascular Clinic, Arnsberg, Germany

5 University of Western Australia Royal Perth Hospital, Perth, Australia

6 Becton Dickinson Peripheral Interventions, Tempe, AZ, USA 